\title{
A escola é uma instituição democratizadora
}

\section{The school is a democratizing institution}

\author{
Alicia Sánchez Jaimes \\ Mestre em Psicologia Clínica, Faculdade de Psicologia da Universidade \\ Nacional Autônoma do México \\ Instituto Politécnico Nacional, Centro de Estudos Científicos e Tecnológicos No. \\ 13 \\ Endereço: Calz Taxqueña 1620, Paseos de Taxqueña, Coyoacán, 04250 \\ Cidade do México, CDMX \\ E-mail: asanchezja@ipn.mx
}

\section{RESUMO}

Podemos começar por definir que, segundo os gregos, democracia é a doutrina política que privilegia a participação do povo no governo para a melhoria das condições de uma sociedade. Com base nesse fato, o desenvolvimento econômico e social está relacionado à democracia, de modo que é de se esperar que as instituições públicas democráticas e a participação cidadã favoreçam diretamente o desenvolvimento social.

Palavras-chave: Desenvolvimento Social, Democracia, Escola.

\section{ABSTRACT}

We can start by defining that, according to the Greeks, democracy is the political doctrine that favors the participation of the people in the government for the improvement of the conditions of a society. Based on this fact, economic and social development is related to democracy, so it is to be expected that democratic public institutions and citizen participation directly favor social development.

Keywords: Social development, Democracy, School.

\section{INTRODUCCIÓN}

Se ha visto en diferentes contextos históricos y en diferentes latitudes que hay unarelación directamente proporcional entre sistemas democráticos y economías saludables y prósperas. Así como la influencia que tienen los sistemas políticos y económicos exitosos en la democratización del bienestar social, entendido como desarrollo social, algunos economistas señalan que 
existe una relación intrínseca entre democracia y el desarrollo social y por tanto se refuerzan mutuamente.

La sociedad actual se encuentra inmersa en grandes transformaciones que van conformando nuevos modelos de interacción social, los procesos históricos, económicos, sociales y culturales han propiciado nuevas maneras de comportamiento y de organización social. La presencia de diversas circunstancias demanda una mayor injerencia de la sociedad civil en la gestión de programas que contribuyan hacia el desarrollo social; se hace necesaria la participación de todos, esto es, una participación colectiva.

En la Declaración del año 2000, los Estados Miembros de las Naciones Unidas declararon que no escatimarían esfuerzo alguno por promover la democracia.

En el Documento Final de la Cumbre Mundial de 2005 se afirma que la democracia, el Estado de derecho y los derechos humanos se encuentran entre los valores yprincipios fundamentales universales e indivisibles de las Naciones Unidas y como tales, son aspectos vinculados entre sí. Estas declaraciones normativas generales se han plasmado en recomendaciones directas elaboradas por el secretario general de las Naciones Unidas sobre los principios y las prácticas subyacentes al trabajo de la Organización en materia de democracia.

Dentro de los marcos normativos las naciones Unidas con relación a la democracia y el desarrollo tienen preocupación por: la igualdad, la participación, la no discriminación, la transparencia y la justicia.

La ONU, ha pugnado por articular el concepto de desarrollo como un derecho humano. En el planteamiento de los Objetivos de Desarrollo del Milenio (ODM) en el año 2000, se puso de manifiesto el compromiso mundial para con la reducción de la pobreza y la generación de un entorno propicio para el desarrollo. En la Cumbre Mundial de 2005, se describió la democracia como un valor universal y se considera que constituye en última instancia una vía para alcanzar

la paz y la seguridad internacional, el progreso y desarrollo económico 
y social y el respeto de los derechos humanos.

\section{2 ¿QUÉ COMPROMISO TIENE LA ESCUELA PARA PROMOVER LA DEMOCRACIA COMO UN INSTRUMENTO PARA ALCANZAR EL DESARROLLO SOCIAL?}

Las instituciones educativas se han planteado entre sus propósitos: proporcionar atodos/as y a cada uno de los estudiantes una educación integral, como un derecho universal, empero, en nuestros días, parece ser un tópico controversial que desatauna cadena de interrogantes, dado que la tarea no es fácil.

La educación afronta muchos desafíos, y tratar de darles solución se convierte en algo complejo, por ejemplo, una de las tareas que se le han asignado a la escuelaes la de coadyuvar en la formación de mejores hombres y mujeres preparados parala vida productiva, con las habilidades necesarias para desenvolverse en la sociedad.

Si bien la Escuela no es la encargada de generar oportunidades de empleo; si puede apoyar para que los estudiantes desarrollen destrezas, actitudes y valores que les sirvan como herramientas para que las desigualdades sociales no se reproduzcan y de esta manera incorporen a la democracia como un estilo de vida.

Otro de los elementos básicos dentro del ambiente escolar, es la equidad, que implica igualdad de oportunidades y justicia social. Dentro de las políticas públicas, el acceso alas oportunidades educativas va asociado al de cobertura.

En este sentido, la educación es un beneficio y obligación que toda sociedad debe cumplir. Por lo tanto, se cree que para que una sociedad sea equitativa, a todos los individuos deben permitírseles el acceso a las oportunidades para educarse.

Han existido muchas posturas en relación al papel de la Escuela, las teorías meritocráticas consideran que es un agente de promoción social y que el acceso a ésta, garantiza la igualdad de oportunidades a todos en el mundo 
laboral. De manera paralela, están las teorías de la reproducción, que han negado que la Escuela tenga alguna injerencia en el desarrollo social de los sujetos, por ejemplo, Bourdieu y Passeron (1977), destacan que la escuela reproduce las desigualdades sociales en forma de desigualdades escolares, a través de una determinadaherencia cultural (Marchesi y Martin, 1998).

A pesar de las inacabables discusiones, los términos democracia y educación debieran formar un binomio indisoluble; como lo señaló Dewey (2001).

La educación para la democracia requiere que la Escuela se instituya como "un espacio en el que al alumno se le trate como un miembro de la sociedad, adquiera sentido de su pertenencia y así contribuya dentro de ella" (Dewey, 2001). Toda sociedad democrática considera que la Escuela es la principal institución para el aprendizaje de la convivencia con otros en un entorno pluralista y de mutuo respeto (Feito, 2009). Otro factor que refuerza el proceso de socialización es que los centros escolares favorecen el acercamiento de toda la comunidad educativa (estudiantes, profesores, autoridades, padres de familia) lo que suscita el contactocon los demás (Dewey, 2001).

La Escuela (Gantiva, 1988) es un escenario privilegiado para la expresión, reproducción y multiplicación de procesos democráticos en tanto brinda la posibilidad de que todos los actores que conforman la comunidad escolar participen en la concepción y concreción de un proyecto que se haya elegido de común acuerdo y que sirva de motor para la escuela. Este proceso de construcción de un proyecto común es denominado autodeterminación, y es presentado por el autor como el objetivo principal de los procesos democráticos. De otra parte, Cajiao (1994) afirma que las dos funciones principales de la escuela son la incorporación de los educandos a la sociedad y la educación práctica enfocada a la supervivencia,el trabajo y el desarrollo de conocimientos.

En este mismo tenor Rodríguez (1997) considera que las instituciones educativas tienen 4 características que hacen de ella un espacio excepcional 
para la construcción de una cultura democrática:

1) El primer espacio de actuación pública del ser humano,

2) Un amplio espectro de incidencia temporal y espacial,

3) Tener nexos con otras instituciones exteriores a ella, y

4) Procurar al individuo la oportunidad de relacionarse con una normatividad institucionalizada en la que se especifican sus derechos y deberes.

Dewey (1997), puntualiza que la democracia es principalmente un modo de vida, en el que los participantes comparten perspectivas y necesidades susceptibles de sersatisfechas por pertenecer al grupo. La democracia no se circunscribe a un Sistema de gobierno, sino que también está configurada por las formas de interactuar de las personas. Es por esto que, las instituciones educativas tienen un rol esencial en la edificación de una sociedad democrática, pues la experiencia de los estudiantes en las escuelas es primordial para la manera como aprenden a experimentar y a relacionarse en entornos sociales más complejos.

Dewey (1997) mencionó que la democracia es sobre todo un modo de vida que se aprende en el interactuar con los otros, que las conductas o actitudes democráticas son las resultantes de la experiencia que los seres humanos adquieren en su paso por diferentes espacios públicos y privados y la escuela modula las diferentes vivencias que los sujetos experimentan.

\section{AHORA BIEN, DEBEMOS CONSIDERAR ¿CÓMO PODEMOS LOS MAESTROS INCIDIR EN ESTE ASPECTO?}

En principio debemos tener claridad en que el profesor desempeña una noble profesión, ya que por ser un potencial agente de cambio puede generar transformaciones en la toma de conciencia acerca de la necesidad de vivir y convivir en espacios en los que se respire democracia; nivel máximo de la equidad, el respeto, la libertad, la solidaridad, la justicia social y la inclusión. En esta transformación, es muy importante que el alumno se percate de la función que tiene como parte de la sociedad y de qué manera su forma de conducirse impacta en ella. 
El profesor al constituirse como un facilitador, como un guía, como un mediador debe ante todo predicar con el ejemplo, manteniendo la congruencia entre lo que dice, lo que piensa y lo que hace. Los docentes tenemos la responsabilidad de crear ambientes escolares democráticos en los que a través de diferentes estrategias, técnicas y actividades se planteen situaciones de conflictos interpersonales y sociales que sirvan como detonantes para poner en juego diferentes funciones cognitivas como: el análisis y la síntesis y a partir de esto se establezcan alternativas de solución; reconociendo al diálogo como el camino más viable.

Paralelo a lo mencionado, al interior de las aulas se debe exaltar un espíritu humanista, en el que se anteponga ante todo el valor del ser humano per se., rescatando los valores que han determinado en mucho su concepto de ser persona y que le son inherentes.

Para tener buenos frutos en este tópico, es necesario vincular los contenidos de aprendizaje con proyectos en los que se desplieguen todos los aspectos relacionados a la democracia. Así como, socializar las experiencias de lo vivido con la finalidad de extender los resultados hacia otros grupos del mismo centro escolary porque no de otros sectores de la sociedad.

Los educadores podemos contribuir con la sociedad reforzando los valores ético- morales que van permitiendo la construcción de la democracia, propiciando que el joven sea consciente de sus responsabilidades, de sus obligaciones, interiorizando la importancia que reviste el hecho de vivir de manera armónica dentro de un grupo social.

Sumado a lo anterior, se debe generar un ambiente en el que los alumnos cobren conciencia de la importancia de, su papel social como futuros ciudadanos, (al alcanzar la mayoría de edad) de su participación en la solución de los problemas sociales; asumiendo los caminos más factibles regidos por parámetros democráticos. Es decir, saber levantar la voz cuando mi conciencia social así me lo exige, cuando es necesario defender mis derechos o los de otros.

La escuela por ser un espacio de socialización se convierte en un nicho 


\section{具是 EDUCATION}

de oportunidades, en donde se pule y ponen en práctica comportamientos ciudadanos democráticos. Es un escenario natural en el que la convivencia se conforma como uno de los saberes que deben ser adquiridos y practicados en la vida escolar y de manera extensa en la vida cotidiana.

\section{CONCLUSIONES}

Debemos considerar que la democracia la podemos reforzar al interior de las aulas, en donde la educación se convierte en un instrumento social para su construcción, ya que abona no solo en la adquisición de conocimientos; sino que potencializa al individuo como un ser pleno consigo mismo y con los demás. Un ser que interiorice la habilidad de saber ser y de saber convivir con los demás; ya que esto le permite ser un individuo transformador.

Así también, los docentes tenemos que propiciar que los estudiantes desarrollen unpensamiento crítico, reflexivo y propositivo ante la problemática nacional y mundial de nuestros días; que conlleve a actitudes y comportamientos en los que se observe el despliegue de valores que se han adquirido en la familia y que ahora la Escuela está dispuesta a fortalecer.

Generar un ambiente democrático al interior de las instituciones educativas no debe ser un tema de moda, sino que debe de instituirse como un estilo de vida escolar y por consecuencia un estilo de vida social. La democracia debe ser visualizada como una condición esencial para abrir el camino hacia un desarrollo social que sea inclusivo y equitativo. 


\section{周易 EDUCATION}

\section{REFERÊNCIAS}

Freire, A. (2011). La educación como práctica de la libertad. México: Siglo XXI.Gutiérrez, G. (1994). Democracia posible. El diseño político de Max Weber. México: Coyoacán.

Magendzo, A. (1996). Curriculum, Educación para la Democracia en la Modernidad.

Bogotá: Antropos.

Organización de las Naciones Unidas (2000). Declaración del milenio. Cumbre delMilenio de las Naciones Unidas (septiembre de 2000)

Disponible en:

https://www.un.org/es/development/devagenda/millennium.shtml

Consultado en: $21 / 05 / 2021$ a las 15:00

Touraine, A. (2006). ¿Qué es la democracia? México: Fondo de Cultura Económica. 